\title{
ASPECTOS PSICOSSOCIAIS QUE ENVOLVEM O CAMINHO DE SANTIAGO
}

Psychosocial aspects involving the Way of Santiago

Laís Perito Abel Joner ${ }^{1}$ Graziela Amboni ${ }^{2}$

\section{RESUMO}

O caminho de Santiago tem se tornando um dos fenômenos mais interessantes da humanidade. A sua identidade, outrora exclusivamente religiosa, está se modificando, dado que, com o passar dos anos, os peregrinos que realizam a jornada estão à procura de outros significados, além do religioso, como autoconhecimento, equilíbrio emocional, desapego material e outras singularidades. O número de indivíduos interessados nessa experiência cresce, sendo assim, o presente estudo tem por objetivo identificar os aspectos psicossociais que envolvem a peregrinação a Santiago de Compostela. Trata-se de uma pesquisa de campo, exploratória, transversal e com abordagem quantiqualitativa, realizada na cidade de Santiago de Compostela -Espanha. Fizeram parte da pesquisa cinquenta indivíduos que finalizaram um dos percursos, nas últimas 48 horas entre os dias 21 e 29 de agosto de 2017. A maioria dos peregrinos descreveu que vivenciou um processo de interiorização e autoconhecimento durante os dias de caminhada, além das experiências com outras culturas. Os entrevistados não demostraram prejuízos cognitivos após a realização do percurso. Quanto à avaliação do estado de humor, a fadiga teve maior média entre os peregrinos. Diante dos resultados expostos, podese concluir que o Caminho de Santiago é capaz de agregar uma pluralidade de experiências subjetivas aos que decidem percorrê-lo.

Palavras-chave: Peregrinação; Santiago de Compostela; Saúde mental; Motivação; Experiências.

\footnotetext{
${ }^{1}$ Curso de Psicologia - Unidade Acadêmica de Ciências da Saúde - UNASAU, Universidade do Extremo Sul Catarinense - UNESC. Correspondência: Rua Domingos Zanatta, 789, Criciúma-SC CEP: 88815-320 - E-mail: laisjoner@gmail.com

${ }^{2}$ Curso de Psicologia - Unidade Acadêmica de Ciências da Saúde - UNASAU, Universidade do Extremo Sul Catarinense - UNESC
} 


\section{ABSTRACT}

The Camino de Santiago has become one of the most interesting phenomena of humanity. His identity, once exclusively religious, is changing, over the years the pilgrims on the journey are seeking other meanings besides religious, such as selfknowledge, emotional balance, material detachment and other singularities. The number of individuals interested in this experience grows, so the present study aims to identify the psychosocial aspects that involve the pilgrimage to Santiago de Compostela. This is an exploratory, cross-sectional, quantitative-qualitative study carried out in the city of Santiago de Compostela, Spain, with fifty people who completed one of the courses in the last 48 hours between 21 and 29 August 2017. Most pilgrims described they experienced a process of interiorization and selfknowledge during the days of walking, as well as experiences with other cultures. Interviewees did not present cognitive impairment after the course. As for the evaluation of the state of the humor, the fatigue had greater average among the pilgrims. Given the results, it can be concluded that the Camino de Santiago is capable of adding a plurality of subjective experiences to those who choose to follow it.

Keywords: Pilgrimage; Santiago de Compostela; Mental health; Motivation; Experiences.

\section{INTRODUÇÃO}

A caminhada está presente na vida do ser humano desde a sua existência, seja por sobrevivência, nomadismo, turismo ou mesmo por práticas religiosas. Assim, a peregrinação nasce vinculada a essas práticas como forma de agregar os aspectos espirituais aos de autoconhecimento e busca pelo seu próprio interior ${ }^{4}$.

A palavra peregrinação origina-se do termo latim peregrinus. Seu sentido original diz respeito a alguém que, através dos campos, viajava para o exterior, não possuindo nenhum sentido religioso. Entretanto, ao longo dos anos, ocorreu uma evolução no seu conceito, atribuindo-se, então, uma conotação religiosa ao termo ${ }^{1}$. Nesse sentido, Duarte ${ }^{2}$ acrescenta que a peregrinação se torna uma viagem religiosa ou espiritual que pode ser realizada individualmente ou em grupos até a um templo ou local sagrado. $O$ autor sustenta que $o$ ato de peregrinar deixou de ser 
um fenômeno isolado para ganhar diferentes formas, dependendo do modo como é realizado.

Para López et al. ${ }^{3}$, a peregrinação pode configurar diferentes funções:

- Suprimento das necessidades humanas: escapar da rotina diária, melhorar a saúde física e mental;

- Função social: desenvolver a comunicação com as pessoas e a socialização;

- Função cultural: agregar conhecimentos culturais e artísticos ao longo do percurso;

- Função econômica: desenvolver a economia de inúmeras cidades e vilas pelos caminhos;

- Função política: união de católicos e muçulmanos, além da aproximação de cidadãos de vários países em um só espaço;

- Função religiosa: acesso à espiritualidade.

No cristianismo, as primeiras peregrinações surgem no séc. IV em direção à Jerusalém e Roma, quando Constantino passa a reconhecer a doutrina Cristã ${ }^{5}$.

Segundo Dalgalarrondo ${ }^{6}$, a religiosidade e espiritualidade sempre foi uma importante instância de significado à vida humana, sendo essencial nos momentos de maior impacto, como luto e doenças. Diante disso, o autor defende que a religião, a espiritualidade e a fé, devam ser privilegiadas nas interlocuções entre saúde e enfermidades mentais.

A partir dos pressupostos acima mencionados, o estudo teve por finalidade identificar os impactos que a peregrinação tem sobre os que decidiram percorrer e finalizar o Caminho de Santiago. Dentre os fatores investigados, procurou-se descrever as características psicossociais que envolvem desde a decisão de se deslocar para o início do percurso até o seu destino final; descrever o perfil psicossocial dos indivíduos que realizam o caminho; identificar se a ideia constituída foi por questões de fé, esporte, traumas, realização pessoal ou curiosidade; compreender o significado que a peregrinação teve para a construção da sua identidade, bem como inquirir, através de entrevistas e testes, as funções cognitivas e estado de humor dos participantes. 
A pesquisa ocorreu na cidade de Santiago de Compostela, com cinquenta indivíduos que finalizaram a caminhada, baseando-se nos aspectos antropológicos, sociológicos e psicológicos. Atualmente, existem poucos estudos que se referem ao tema peregrinação, por este motivo, foram recolhidas informações dos próprios peregrinos, correlacionando com livros e artigos pertinentes ao tema.

Primeiramente, apresenta-se uma contextualização sobre a história e o significado do Caminho de Santiago, seguido da apresentação dos participantes, resultados dos testes e análise qualitativa do estudo, incluindo seus depoimentos, percepções e experiências.

Não foi possível constatar todos os fatores emocionais e psicossociais que envolvem essa experiência, devido ao tempo e complexidade sobre o tema. Embora as informações resultantes não sejam generalizáveis, a investigação contribuiu para compreender quais os aspectos psicossociais que envolvem o Caminho de Santiago, bem como o significativo aumento de indivíduos interessados em realizar a jornada.

\section{O CAMINHO DE SANTIAGO}

Segundo o cristianismo, após a morte de Jesus Cristo, os apóstolos saíram pelo mundo a fim de pregar o evangelho. Tiago, um desses apóstolos, escolheu a região da Galiza na Espanha para levar a palavra de seu mestre. No entanto, sem obter êxito com a evangelização, retornou à Palestina, onde foi morto decapitado a mando de Herodes. Teodoro e Atanásio, discípulos e seguidores de Tiago, levaram seus restos mortais de volta para Espanha. Passando pelo estreito de Gibraltar, circundaram a Lusitânia e em sete dias chegaram a Iria Flávia, na Galiza. Muitas lendas contam como solicitaram a permissão para enterrar o corpo do Apóstolo, uma delas se refere a permissão da Rainha Lupa, que os denunciou a um governador Romano e, na fuga, uma intervenção divina os livra da perseguição. Lupa, então, oferece-os uma manada de touros selvagens para auxiliar no transporte do corpo. Enfrentam um dragão e, finalmente, enterram-no no monte Libredón. Relíquias são colocadas junto ao seu corpo em um túmulo de mármore 
envolto por uma simples capela. Teodoro e Atanásio guardaram o corpo do apóstolo Tiago até o fim de suas vidas 5 .

De acordo com algumas das lendas associadas ao Caminho de Santiago, durante 800 anos, o túmulo do apóstolo permaneceu esquecido, até que Pelayo, um eremita, observou durante noites seguidas chuvas de estrelas acompanhadas de um canto celestial. Essas estrelas avistadas por Pelayo formavam um caminho vindo do norte do oriente, o local onde se encontrava o corpo do apóstolo ${ }^{8}$.

Esta suposta redescoberta do túmulo do Apóstolo, acontece numa época crucial para a história da Península Ibérica e da Europa cristã, em geral com o início da Reconquista peninsular pelos cristãos do norte da ibéria e com o recuo das forças muçulmanas. Tal achado veio há época elevar a moral e a fé, principalmente a dos soldados e guerreiros que passaram a gritar o nome do santo nos campos de batalha como grito de guerra e o apelidaram mesmo de "matamoros"- mata mouros 4 .

Os mouros eram os muçulmanos nascidos na Ibéria que não podendo expressar sua fé eram perseguidos e obrigados a aceitar as condições dos cristãos para ali permanecerem. Ferdinando II e Isabel deu-lhes o direito de professar sua religião, todavia os maus tratos e a discriminação persistiam. Mesmo os mouros aceitando o cristianismo, não deixaram totalmente seus costumes, sendo expulsos por volta de $1609^{9}$.

Após o recuo dos mouros, aproximadamente em 849, abriu-se o mais conhecido caminho da peregrinação, o Francês. Vinham, então, peregrinos de toda a Europa e se concentravam no centro da França, partindo para quatro rotas, a de Tours, a de Limoges, a de Le Puy e a de Toulouse. Entravam na Espanha por Roncesvales 4 .

Monges se estabeleceram ao longo das rotas construindo seminários, igrejas, refúgios, casas de assistência aos peregrinos e, inclusive, hospitais psiquiátricos. Entretanto, somente a partir do ano 1000 que houve a popularização do Caminho. A Peste Negra no século XIV e a Reforma Protestante no século XVI, levou o caminho ao declive. João Calvino, Martinho Lutero e Erasmo Roterdão diziam que as viagens eram inúteis, e peregrinos de países como Inglaterra, Alemanha, Países Baixos e Escandinávia que aderiram ao protestantismo, não realizavam mais a rota ${ }^{5}$ 
No final do século $X X$, as peregrinações tomaram força novamente. No ano de 1993, o caminho Francês, mais utilizado pelos peregrinos, foi considerado patrimônio da humanidade pela UNESCO (Organização das Nações Unidas para Educação, Ciência e Cultura), por estar repleto de marcos arquitetônico dos períodos romanos, barroco, góticos e neoclássicos. Por todo seu significado, a cidade de Santiago de Compostela, também, foi declarada pela UNESCO como patrimônio da humanidade e é considerada a terceira mais sagrada do cristianismo, depois de Jerusalém e Roma ${ }^{4}$.

Não existe somente um percurso que se denomina Caminho de Santiago. Torre et al. ${ }^{10}$ acrescentam que essa peregrinação possui diversas rotas históricas, porém existem condições para que tais percursos sejam denominados como Caminho de Santiago, a saber:

[...] existência de um traçado histórico definido e sua cartografia; ii) a toponímia de algumas povoações por onde passam as rotas estar de certo modo relacionada com o Caminho (topónimos religiosos); iii) a existência de uma rede de hospitais (Misericórdias) ao longo do Caminho, bem como arquitetura associada (monumentos, cruzeiros, pontes românicas...); iv) a existência de documentos históricos e lendas associadas à peregrinação jacobeia; v) a existência de igrejas e capelas com iconografia associada ao apóstolo ${ }^{10}$.

O Caminho Francês, composto por cerca de 800 quilômetros, tem seu início na cidade francesa de Saint Jean Pied du Port, passando por cinquenta cidades, como Roncesvalles, Pamplona e León. Esse caminho foi uma criação dos monges de Cluny e é o mais utilizado ainda nos dias de hoje ${ }^{4}$. Atualmente, destacam-se sete caminhos, incluindo o Francês, o Caminho do Norte, conhecido também como Cantábrio, o Caminho Português, o Caminho Inglês, o Caminho Primitivo, a Rota Marítimo-fluvial e a Via de la Plata ${ }^{2}$.

Segundo Santos e Silva ${ }^{11}$, as novas peregrinações de certa forma modificaram o sentido original. Atualmente, são compostas de outros interesses, indo além da fé, como turismo, esporte ou autoconhecimento.

\section{ASPECTOS PSICOSSOCIAIS}

De acordo com o relatório sobre Saúde no mundo, elaborado pela Organização Mundial da Saúde (OMS) em 2001, a definição de saúde mental varia conforme a cultura do indivíduo, envolvendo conceitos de bem-estar individual, 
autoeficácia percebida, autonomia e outros aspectos subjetivos. Por esses motivos mencionados, torna-se ilusório tentar definir completamente saúde mental, visto que sua concepção vai além da ausência de transtornos mentais. ${ }^{34}$

Sampaio ${ }^{12}$ explana que saúde e doença são conceitos vinculados ao contexto socioeconômico e cultural, tanto em suas produções como na percepção do saber que investiga e propõe soluções. Para Machado ${ }^{13}$, para mensurar uma conduta, é preciso compará-la com ela mesma e com outros comportamentos aceitos em cada sociedade.

Minayo ${ }^{15}$ destaca que 0 processo saúde-doença se refere a um fenômeno clínico e sociológico experienciado em diferentes culturas. Deste modo, qualquer ação de diagnóstico, tratamento e prevenção deve levar em conta o meio em que o indivíduo está inserido, considerando suas crenças, condutas e princípios.

Segundo Dalgalarrondo 6 , a religiosidade, as crenças, a fé e a espiritualidade sempre foram uma importante instância de significado à vida humana, sendo essencial nos momentos de maior impacto, como luto e doenças. Diante dessa perspectiva, o autor defende que a religião deva ser privilegiada nas interlocuções entre saúde e enfermidades mentais.

Para Murakami e Campos ${ }^{16}$ :

A religiosidade implica em uma mobilização de energia positiva, a fé. As pessoas que têm fé sentem-se mais fortes para enfrentar dificuldades e continuar a lutar pela sua sobrevivência, acreditando que serão curadas dos seus males. A fé faz o indivíduo acreditar numa provisão sobrenatural, capaz de intervir favoravelmente em sua situação concreta de vida e, especialmente, no caso do adoecimento mental, no curso da doença e nos seus efeitos na vida quotidiana.

A peregrinação nasce como um dos grandes fenômenos dentro das religiões. Meslin ${ }^{17}$ propõe que tal acontecimento faz com que 0 indivíduo experimente os seus próprios limites e o domínio do seu sofrimento. Diante dessa perspectiva, Dalgalarrondo ${ }^{6}$ destaca que, nas últimas décadas, novos estudos têm buscado explicar as possíveis relações entre experiências religiosas e o funcionamento cerebral. $O$ autor, também, considera que qualquer tentativa de enquadrar tais experiências em um só enfoque, torna-se inviável, pois a relação do homem com a fé e a religiosidade vai além daquilo que as ciências naturais podem explicar. Contudo, considerando que qualquer experiência humana passa por relações neuronais, o próprio autor define que as colocações feitas acima podem 
ser contra argumentadas, uma vez que o cérebro é o órgão mais envolvido com o comportamento humano, pensamentos e sentimentos.

Para além dos aspectos subjetivos envolvidos, peregrinar é também movimentar o corpo. Pesquisas apontam os efeitos positivos dessas práticas para a saúde mental e o bem-estar geral, como a diminuição da ansiedade, estresse, depressão, melhoria do autoconceito, bem-estar psicológico e estado de humor de indivíduos sedentários ${ }^{18}$. Não obstante, antes da decisão de movimentar-se fisicamente, o indivíduo que decide iniciar uma peregrinação é especialmente envolvido por movimentos internos. Tal dinâmica o faz refletir sobre si e o que levar consigo, deixando de lado seus apegos para colocar na mochila somente o necessário à sua sobrevivência por alguns dias ${ }^{19}$.

$\mathrm{Na}$ condição da pós-modernidade, as peregrinações têm adquirido um novo impulso que vem tanto da revalorização de tradições pré-cristãs (europeia, orientais e indígenas) quanto da emergência das religiões do self, que vão enfatizar a dimensão da experiência pessoal e a imanência do sagrado na paisagem e na natureza. Valores como o cuidado do corpo, a ecologia, o sujeito psicológico como referência primeira para a vivência da fé têm encontrado nas peregrinações uma estrutura e um modelo ritual para se expressarem ${ }^{19}$.

Diante de tal discussão, Steil e Carneiro ${ }^{20}$ ressaltam que a experiência de peregrinar está se ressignificando, passando de experiência religiosa para cultural e social. Para os autores, tal movimento permite a elaboração de práticas pessoais e coletivas enquanto dimensões humanas. Assim, toda peregrinação gera um espaço de educação, que perpassa a experiência do tornar-se e vir-a-ser no processo de desenvolvimento e construção da identidade social dos indivíduos.

\section{METODOLOGIA}

Para realização deste estudo, optou-se por um enfoque quantiqualitativo, exploratório e transversal. Sampieri et al. ${ }^{21}$ afirmam que a pesquisa quantiqualitativa é definida como modelo misto que tem como objetivo constituir e integrar as partes quantitativas e qualitativas, sendo que essas se combinam durante todo o processo da análise.

Conforme Creswell ${ }^{22}$, um dos objetivos da pesquisa mista apoia-se na busca de explorar as visões dos participantes e usá-las para desenvolver e testar determinado instrumento, utilizando uma amostra da população ou obter 
resultados estatísticos e quantitativos através de uma amostra. Por conseguinte, promover um acompanhamento com algumas pessoas da amostra, a fim de investigar ou explorar esses resultados com maior profundidade. Diante do exposto, é desta forma que este estudo foi desenvolvido, buscando conciliar esses dois objetivos. Para Sampieri et al. ${ }^{21}$, alguns fenômenos e problemas que as ciências enfrentam são complexos e diversos, o que torna difícil o uso de um único enfoque.

O estudo obteve aprovação do Comitê de Ética em Pesquisa da Universidade do Extremo Sul Catarinense, com Parecer $n^{\circ} 2.148 .383$ e CAAE $n^{\circ}$ 68937417.5.0000.0119. A investigação foi realizada em campo, no mês de agosto de 2017, pois se constou a necessidade de recolher e registrar, de forma ordenada, os dados fornecidos pelos depoimentos para, assim, atingir os objetivos propostos. O local da investigação foi a praça do Obradoiro, localizada na Rua de San Francisco, 38, e o Albergue Seminário Menor localizado na Av. de Quiroga Palacios, 2, na cidade de Santiago de Compostela, La Coruña, Espanha. A praça do Obradoiro é o principal ponto de chegada dos peregrinos e nela eles permanecem para descansar e demostrar que finalizaram o percurso. O Albergue Seminário Menor foi escolhido pela sua grandiosidade em número de vagas oferecidas.

A amostra é composta por um total de cinquenta indivíduos de quatorze nacionalidades diferentes que durante alguns dias decidiram caminhar e concretizar o trajeto. Foram recolhidas as respostas até 48 horas após sua chegada em Santiago de Compostela. Com intenção de salvaguardar a confidencialidade, a identidade dos entrevistados foi preservada, sendo apresentados por números.

Para atender aos objetivos do presente estudo, três instrumentos de coleta de dados foram utilizados: um roteiro de entrevista, um inventário de estado de humor, denominado Perfil dos Estados de Humor (POMS); e um teste intitulado Mini Exame do Estado Mental (MEEM), com total concordância dos sujeitos, obtida através do Termo de Consentimento Livre e Esclarecido -TCLE. A entrevista foi elaborada e registrada pela pesquisadora. Segundo Richardson ${ }^{23}$, a entrevista "é uma técnica importante que permite o desenvolvimento de uma estreita relação entre as pessoas. É um modo de comunicação no qual determinada informação é transmitida". 
O Inventário de Escala de Humor (POMS) permitiu mensurar a intensidade de estados de humor. A escala original foi formulada em Inglês e é composta por sessenta e cinco itens, contendo seis subdivisões: tensão, depressão, raiva, vigor, fadiga e confusão mental. Os autores McNair, Loor e Droppleman desenvolveram esse instrumento no final da década de 50 para observar diferentes momentos de flutuação de humor de pacientes psiquiátricos. Atualmente, esse inventário é muito utilizado no contexto esportivo ${ }^{24}$.

O teste Mini Exame do Estado Mental (MEEM), outrossim, foi aplicado nos participantes. Esse teste possibilita avaliar as funções da consciência, bem como identificar perdas cognitivas. De acordo com Fostein et al..$^{25}$, o MEEM aborda questões referentes à retenção e evocação, orientação temporal e espacial, atenção, cálculo e linguagem - afasia, apraxia e habilidade construcional. Os valores mais elevados indicam maior desempenho cognitivo. A duração da aplicação de todos os instrumentos foi de aproximadamente 40 minutos.

Para as análises estatísticas, utilizou-se o software IBM - SPSS (Statistical Package for the Social Sciences) versão 20.0. A construção de tabelas foi realizada no software Microsoft Word 2010. Os valores das medidas das variáveis foram apresentados por: média, desvio-padrão, mínimo, máximo e intervalo de confiança (IC 95\%).

\section{RESULTADOS E DISCUSSÃO}

A amostra do presente estudo foi composta por 50 peregrinos, sendo que $54,0 \%$ (27 peregrinos) são do gênero masculino, enquanto que 46,0\% (23 peregrinos) são do gênero feminino. A média de idade da amostra geral foi de $40,14 \pm 15,40$, do gênero feminino foi de $38,78 \pm 14,18$ e do masculino de $41,30 \pm 16,55$. Sob uma ótica quantitativa, o número de indivíduos que realizam alguma das variantes do caminho tem aumentado significativamente. Segundo dados disponibilizados pela Oficina del Peregrino ${ }^{26}$, em 2004, concluíram o Caminho de Santiago 179.944 peregrinos e, em 2016, 277.854 pessoas completaram a jornada.

Quanto à escolaridade, a maioria dos peregrinos, 62,0\% (31 peregrinos), possui o ensino superior completo. A nacionalidade mais dominante dos 
entrevistados foi a espanhola, 34,0\% (17 peregrinos), seguidos de italianos, $28,0 \%$ (14 peregrinos). Com relação ao estado civil, $64,0 \%$ (32 peregrinos) são solteiros (as). A religião católica aparece como dominante entre os entrevistados, correspondendo a 78,0\% (39 peregrinos). Quanto a ser praticante ou não da religião, $60,0 \%$ (30 peregrinos) afirmam ser ativos. Quando questionados se fazem ou não uso de medicação psiquiátrica durante o seu dia a dia, 92,0\% (46 peregrinos) afirmam não fazer uso de nenhum tipo de substância (Tabela 1).

Tabela 1 - Caracterização da amostra $(n=50)$

\begin{tabular}{|c|c|c|c|}
\hline \multirow{2}{*}{ Variável } & \multirow{2}{*}{$\begin{array}{c}\text { Média } \pm \text { DP } \\
\text { ou n (\%) }\end{array}$} & \multicolumn{2}{|c|}{ IC 95\% } \\
\hline & & Inf. & Sup. \\
\hline Gênero & & & \\
\hline Masculino & $27(54,0 \%)$ & 40,0 & 68,0 \\
\hline $\begin{array}{l}\text { Feminino } \\
\text { Idade }\end{array}$ & $23(46,0 \%)$ & 32,0 & 60,0 \\
\hline Amostra geral & $40,14 \pm 15,40$ & $36,18 \pm 12,94$ & $44,50 \pm 17,78$ \\
\hline Feminino & $38,78 \pm 14,18$ & $32,57 \pm 10,82$ & $45,00 \pm 15,99$ \\
\hline Masculino & $41,30 \pm 16,55$ & $34,93 \pm 12,10$ & $48,13 \pm 19,82$ \\
\hline \multicolumn{4}{|l|}{ Escolaridade } \\
\hline Superior completo & $31(62,0 \%)$ & 48,0 & 76,0 \\
\hline Ensino Médio & $11(22,0 \%)$ & 12,0 & 34,0 \\
\hline Superior incompleto & $07(14,0 \%)$ & 6,00 & 24,0 \\
\hline $\begin{array}{l}\text { Ensino Fundamental } \\
\text { Nacionalidade }\end{array}$ & $01(2,00 \%)$ & 0,00 & 6,00 \\
\hline Espanha & $17(34,0 \%)$ & 20,0 & 46,0 \\
\hline Itália & $14(28,0 \%)$ & 16,1 & 42,0 \\
\hline Brasil & $03(6,00 \%)$ & 0,00 & 14,0 \\
\hline EUA & $03(6,00 \%)$ & 0,00 & 14,0 \\
\hline Portugal & $02(4,00 \%)$ & 0,00 & 10,0 \\
\hline Alemanha & $02(4,00 \%)$ & 0,00 & 10,0 \\
\hline Peru & $02(4,00 \%)$ & 0,00 & 10,0 \\
\hline Escócia & $01(2,00 \%)$ & 0,00 & 6,00 \\
\hline África do Sul & $01(2,00 \%)$ & 0,00 & 6,00 \\
\hline Croácia & $01(2,00 \%)$ & 0,00 & 6,00 \\
\hline Colômbia & $01(2,00 \%)$ & 0,00 & 6,00 \\
\hline Argentina & $01(2,00 \%)$ & 0,00 & 6,00 \\
\hline Equador & $01(2,00 \%)$ & 0,00 & 6,00 \\
\hline Lituânia & $01(2,00 \%)$ & 0,00 & 6,00 \\
\hline \multicolumn{4}{|l|}{ Estado civil } \\
\hline Solteiro (a) & $32(64,0 \%)$ & 50,0 & 76,0 \\
\hline Casado (a) & $11(22,0 \%)$ & 12,0 & 34,0 \\
\hline Divorciado (a) & $04(8,00 \%)$ & 2,00 & 16,0 \\
\hline Separado (a) & $02(4,00 \%)$ & 0,00 & 10,0 \\
\hline União estável & $01(2,00 \%)$ & 0,00 & 6,00 \\
\hline
\end{tabular}

Revista Inova Saúde, Criciúma, vol. 10, n. 1, fev. 2020. 


\begin{tabular}{llll} 
Religião & & & \\
Católico & $39(78,0 \%)$ & 66,0 & 88,0 \\
$\quad$ Ateu & $06(12,0 \%)$ & 4,00 & 22,0 \\
$\quad$ Outras & $03(6,00 \%)$ & 0,00 & 14,0 \\
$\begin{array}{l}\text { Protestante } \\
\text { Judeu }\end{array}$ & $01(2,00 \%)$ & 0,00 & 6,00 \\
& $01(2,00 \%)$ & 0,00 & 6,00 \\
Praticante & & & \\
$\quad$ Sim & $30(60,0 \%)$ & 46,0 & 74,0 \\
$\quad$ Não & $20(40,0 \%)$ & 26,0 & 54,0 \\
substância psicoativa & & & \\
$\quad$ Sim & $04(8,00 \%)$ & 2,00 & 16,0 \\
Não & $46(92,0 \%)$ & 84,0 & 98,0 \\
MEEM & & & \\
Escore & $28,0 \pm 1,77$ & $27,48 \pm 1,31$ & $28,46 \pm 2,20$ \\
\hline
\end{tabular}

Legenda: DP: Desvio-Padrão; $n=$ número absoluto; \%: porcentagem; IC: Intervalo de Confiança; Inf.: Limite inferior; Sup.: Limite superior; EUA: Estados Unidos da América.

Fonte: Dados da pesquisa.

No que concerne aos transtornos, observa-se que $28,0 \%$ (14 peregrinos) foram diagnosticados com algum tipo de transtorno mental. Desses, 21,4\% (03 peregrinos), diagnosticados com depressão, seguido de 14,30\% (02 peregrinos) com transtorno de pânico e, na mesma proporção, de estresse. Os estudos de Martín e Monteserín ${ }^{27}$ apontam que é comum encontrar indivíduos com transtornos mentais que buscam no Caminho de Santiago soluções para suas enfermidades psíquicas. No entanto, muitas pessoas saudáveis, procuram no percurso um ansiolítico vital que não encontram em suas vidas apressadas. Os autores afirmam que alguns indivíduos com doenças mentais pré-existentes sofrem recaídas ou exacerbações enquanto estão fazendo o trajeto e as razões podem incluir: fadiga, problemas de relacionamento ou abandono do tratamento psiquiátrico. A média do Mini Exame do Estado Mental-MEEM dos peregrinos foi de $28,0 \pm 1,77$. Nenhum dos entrevistados apresentou prejuízos cognitivos no momento da sua chegada.

Tabela 2 - Transtornos mentais $(n=14)$

\begin{tabular}{cccc}
\hline Variável & Média \pm DP & \multicolumn{2}{c}{ IC 95\% } \\
ou n (\%) & Inf. & Sup. \\
Transtorno mental & & & \\
Sim & $14(28,0 \%)$ & 16,0 & 42,0 \\
Não & $35(70,0 \%)$ & 56,0 & 82,0 \\
Não respondeu & $01(2,00 \%)$ & 0,00 & 6,00 \\
\hline \hline
\end{tabular}

Revista Inova Saúde, Criciúma, vol. 10, n. 1, fev. 2020.

ISSN 2317-2460 


\section{Tipo de diagnóstico}

Depressão

Transtorno de pânico

Estresse

Transtorno de estresse pós-traumático

Ansiedade

Transtorno bipolar

Depressão e ansiedade

Bulimia, depressão, ansiedade e transtorno de pânico

Amnésia

$\begin{array}{ccc}03(21,40 \%) & 0,00 & 42,90 \\ 02(14,30 \%) & 0,00 & 35,70 \\ 02(14,30 \%) & 0,00 & 35,70 \\ 01(7,10 \%) & 0,00 & 21,40 \\ 01(7,10 \%) & 0,00 & 21,40 \\ 01(7,10 \%) & 0,00 & 21,40 \\ 01(7,10 \%) & 0,00 & 21,40 \\ 01(7,10 \%) & 0,00 & 21,40 \\ 01(7,10 \%) & 0,00 & 21,40 \\ 01(7,10 \%) & 0,00 & 21,40\end{array}$

Depressão e transtorno de pânico

Legenda: DP: Desvio-Padrão; $\mathrm{n}=$ número absoluto; \%: porcentagem; IC: Intervalo de Confiança; Inf.: Limite inferior; Sup.: Limite superior.

Fonte: Dados da pesquisa.

No que se refere a variante percorrida, em sua maioria, o percurso com maior frequência escolhido foi o Caminho Francês, sendo realizado por 40,0\% (20 peregrinos). Em segunda colocação está o Caminho Português, realizado por 24,0\% (12 peregrinos) e, assim, seguem em menor proporção os demais caminhos, como: Caminho do Norte, 12,0\% (06 peregrinos); Caminho Primitivo, 8,00\% (04 peregrinos), entre outros. Ao longo dos séculos, as rotas geográficas passaram por diversas modificações. O único ponto irremovível é o destino final, Compostela, sendo o Francês o trajeto mais utilizado, por ser o mais sinalizado, provido de albergues, atividades turísticas e culturais $^{27}$. Quanto à distância em quilômetros percorridos por esses peregrinos, a média foi de $435,90 \pm 334,72$, sendo no mínimo percorrido 112 quilômetros e no máximo 1600 quilômetros. No que diz respeito ao

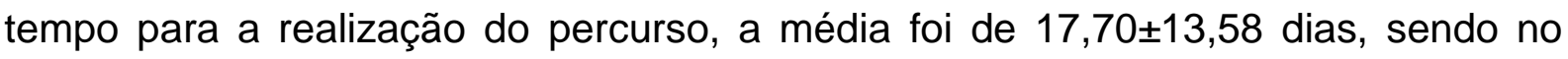
mínimo de quatro dias e no máximo de 54 dias. Neste percurso, 52,0\% (26 peregrinos) fizeram o caminho sozinho e 92,0\% (46 peregrinos) não fizeram uso de substância psicoativa durante o percurso.

Quando questionados se fariam novamente o percurso, 86,0\% (43 peregrinos) responderam que sim (Tabela 3). Silva e Santos ${ }^{11}$ entendem que "O caminhar constrói uma história que se experimenta passo a passo, com vivências, interações, intenções e intensidades distintas para cada peregrino." De acordo com observações realizadas pela pesquisadora, pode-se concluir que indivíduos que percorreram caminhos mais curtos e/ou em grupos demostravam maior inquietação e ansiedade, comparados aos que concretizaram o caminho por rotas mais longas 
em mais dias e desacompanhados. Para Martinez ${ }^{28}$, muitos peregrinos relatam um processo de interiorização e autorreflexão existencial, devido a dias de solidão, silêncio e exaustão das caminhadas.

Tabela 3 - Caracterização do caminho $(n=50)$

\begin{tabular}{|c|c|c|c|}
\hline \multirow{2}{*}{ Variável } & \multirow{2}{*}{$\begin{array}{c}\text { Média } \pm \text { DP } \\
\text { ou n (\%) }\end{array}$} & \multicolumn{2}{|c|}{ IC 95\% } \\
\hline & & Inf. & Sup. \\
\hline \multicolumn{4}{|l|}{ Caminho percorrido } \\
\hline Caminho Francês & $20(40,0 \%)$ & 28,0 & 54,0 \\
\hline Caminho Português & $12(24,0 \%)$ & 12,0 & 36,0 \\
\hline Caminho do Norte & $06(12,0 \%)$ & 4,00 & 22,0 \\
\hline Caminho Primitivo & $04(8,00 \%)$ & 2,00 & 16,0 \\
\hline Próprio Caminho & $03(6,00 \%)$ & 0,00 & 12,0 \\
\hline Caminho de Finisterra & $02(4,00 \%)$ & 0,00 & 10,0 \\
\hline Caminho Inglês & $01(2,00 \%)$ & 0,00 & 6,00 \\
\hline Sanabrês & $01(2,00 \%)$ & 0,00 & 6,00 \\
\hline Caminho Espiritual & $01(2,00 \%)$ & 0,00 & 7,90 \\
\hline \multicolumn{4}{|l|}{ Percurso } \\
\hline Quilômetros & $435,90 \pm 334,72$ & $350,00 \pm 265,03$ & $539,57 \pm 411,88$ \\
\hline Quantos dias & $17,70 \pm 13,58$ & $14,24 \pm 10,47$ & $21,86 \pm 16,23$ \\
\hline \multicolumn{4}{|l|}{ Fez o caminho sozinho } \\
\hline Sim & $26(52,0 \%)$ & 38,0 & 66,0 \\
\hline Não & $24(48,0 \%)$ & 34,0 & 62,0 \\
\hline \multicolumn{4}{|l|}{ Usou substância psicoativa } \\
\hline Sim, usei no caminho & $04(8,00 \%)$ & 2,00 & 16,0 \\
\hline $\begin{array}{l}\text { Não, não usei no caminho } \\
\text { Faria novamente }\end{array}$ & $46(92,0 \%)$ & 84,0 & 98,0 \\
\hline Sim & $43(86,0 \%)$ & 76,0 & 94,0 \\
\hline Não & $07(14,0 \%)$ & 6,0 & 24,0 \\
\hline
\end{tabular}

Legenda: DP: Desvio-Padrão; n= número absoluto; \%: porcentagem; IC: Intervalo de Confiança; Inf.: Limite inferior; Sup.: Limite superior.

Fonte: Dados da pesquisa.

Sobre as experiências e sensações durante o percurso, observa-se que $38,0 \%$ (19 respondentes) negam ter tido alguma experiência mística. No tocante a sentir-se guiado por uma voz ou imagem durante os dias de caminhada, 26,0\% (13 peregrinos) afirmam ter tido tal experiência.

Quando questionados sobre pensar em desistir durante o percurso, $26,0 \%$ (13 peregrinos) afirmaram que tiveram a vontade de abandonar o caminho (Tabela 4). 
Tabela 4 - Experiências e sensações durante o percurso $(n=50)$

\begin{tabular}{cccc}
\hline Variável & Média \pm DP & \multicolumn{2}{c}{ IC $95 \%$} \\
ou n (\%) & Inf. & Sup. \\
Experiência mística & & & \\
Sim & $19(38,0 \%)$ & 24,0 & 52,0 \\
Não & $30(60,0 \%)$ & 46,0 & 74,0 \\
Não respondeu & $01(2,00 \%)$ & 0,00 & 6,00 \\
Sentiu-se guiado por voz ou imagem & & & \\
Sim & $13(26,0 \%)$ & 14,0 & 40,0 \\
Não & $36(72,0 \%)$ & 58,0 & 84,0 \\
Não respondeu & $01(2,00 \%)$ & 0,00 & 8,00 \\
Pensou em desistir & & & \\
Sim & $13(26,0 \%)$ & 14,0 & 38,0 \\
Não & $37(74,0 \%)$ & 62,0 & 86,0 \\
\hline
\end{tabular}

Legenda: DP: Desvio-Padrão; $n=$ número absoluto; \%: porcentagem; IC: Intervalo de Confiança; Inf.: Limite inferior; Sup.: Limite superior.

Fonte: Dados da pesquisa.

Sobre as sensações durante a caminhada, $36,0 \%$ (18 peregrinos) afirmaram ter perdido a noção de espaço e $56,0 \%$ (28 peregrinos) a noção de tempo.

Dentre os entrevistados, $8,00 \%$ (04 peregrinos) sentiram frio irregular e $12,0 \%$ (06 peregrinos) referenciaram ondas de calor. Quanto a sensação de palpitação, foi negada por 98,0\% (49 peregrinos) e, nesta mesma proporção, foram negadas as sensações de sudorese e medo da morte eminente (Tabela 5).

Tabela 5 - Sensações durante o percurso $(n=50)$

\begin{tabular}{cccc} 
Variável & $\begin{array}{c}\text { Média } \pm \text { DP } \\
\text { ou n (\%) }\end{array}$ & \multicolumn{2}{c}{ IC 95\% } \\
Inf. & Sup. \\
Perder noção de espaço & & & \\
Sim & $18(36,0 \%)$ & 22,0 & 50,0 \\
Não & $32(64,0 \%)$ & 50,0 & 78,0 \\
Perder noção de tempo & & & \\
Sim & $28(56,0 \%)$ & 42,0 & 69,9 \\
Não & $22(44,0 \%)$ & 30,1 & 58,0 \\
Frio & & & \\
Sim & $04(8,00 \%)$ & 2,00 & 16,0 \\
Não & $46(92,0 \%)$ & 84,0 & 98,0
\end{tabular}




$\begin{array}{ccrr}\text { Calor } & & & \\ \text { Sim } & 06(12,0 \%) & 4,00 & 22,0 \\ \text { Não } & 44(88,0 \%) & 78,0 & 96,0 \\ \text { Palpitação } & & & \\ \text { Sim } & 01(2,00 \%) & 0,00 & 6,00 \\ \text { Não } & 49(98,0 \%) & 94,0 & 100,0 \\ \text { Tremor } & & & \\ \text { Sim } & 02(4,10 \%) & 0,00 & 10,2 \\ \text { Não } & 47(95,9 \%) & 89,8 & 100,0 \\ \text { Sudorese } & & & \\ \text { Sim } & 01(2,00 \%) & 0,00 & 6,00 \\ \text { Não } & 49(98,0 \%) & 94,0 & 100,0 \\ \text { Sim } & & & \\ \text { Não } & 01(2,00 \%) & 0,00 & 6,00 \\ \text { Medo, } & 49(98,0 \%) & 94,0 & 100,0\end{array}$

Legenda: DP: Desvio-Padrão; n= número absoluto; \%: porcentagem; IC: Intervalo de Confiança; Inf.: Limite inferior; Sup.: Limite superior.

Fonte: Dados da pesquisa.

Quanto à avaliação do perfil de humor dos peregrinos, observa-se que

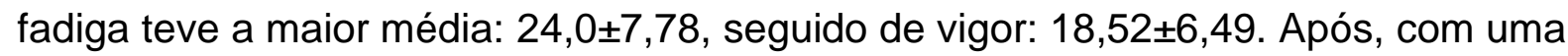

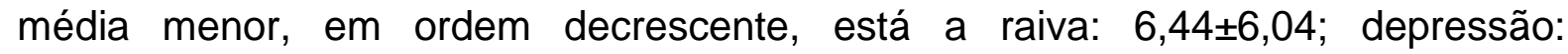

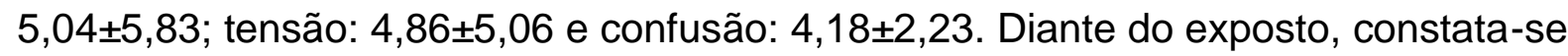
que os dias de intensa caminhada proporcionaram um nível elevado do estado de humor fadiga. Do mesmo modo, o estado de humor vigor obteve um alto índice entre os participantes, fato justificado por se perceberem capazes de concluir a jornada sem prejuízos físicos ou mentais.

Tabela 6 - POMS

\begin{tabular}{cccc}
\hline Variável & Média \pm DP & \multicolumn{2}{c}{ IC 95\% } \\
& & Inf. & Sup. \\
Tensão & $4,86 \pm 5,06$ & $3,56 \pm 3,70$ & $6,34 \pm 6,13$ \\
Depressão & $5,04 \pm 5,83$ & $3,60 \pm 3,76$ & $6,74 \pm 7,56$ \\
Raiva & $6,44 \pm 6,04$ & $4,88 \pm 3,94$ & $8,12 \pm 7,63$ \\
Vigor & $18,52 \pm 6,49$ & $16,60 \pm 5,51$ & $20,22 \pm 7,32$ \\
Fadiga & $24,0 \pm 7,78$ & $6,34 \pm 4,36$ & $9,30 \pm 6,75$ \\
Confusão & $4,18 \pm 2,23$ & $3,56 \pm 1,75$ & $4,78 \pm 2,65$ \\
\hline
\end{tabular}

Legenda: DP: Desvio-Padrão; n= número absoluto; \%: porcentagem; IC: Intervalo de Confiança; Inf.: Limite inferior; Sup.: Limite superior.

Revista Inova Saúde, Criciúma, vol. 10, n. 1, fev. 2020.

ISSN 2317-2460 
Fonte: Dados da pesquisa.

A análise qualitativa, feita a partir das respostas abertas fornecidas pelos entrevistados, foi dividida por categorias, assim apresentadas: motivação para realizar o Caminho de Santiago, impacto do caminho na construção da sua identidade e quais as experiências o percurso lhes proporcionou. As categorias e subcategorias, quando houver, serão descritas a seguir.

Sobre a motivação para iniciar o Caminho de Santiago, dez indivíduos disseram que a decisão foi tomada com a intenção de testar seus limites, ou seja, conhecerem suas capacidades físicas e/ou mentais. Nesta categoria, um dos entrevistados descreveu: "[...] colocar-me a prova psicologicamente e fisicamente". (PEREGRINO 2). Outro peregrino referiu: "[...] por mim mesmo, uma coisa pessoal, me compreender para afrontar a vida e colocar-me em jogo". (PEREGRINO 40).

Outra motivação citada pelos entrevistados foi à busca por conhecer novas pessoas e, assim, socializar com elas. Sete dos cinquenta entrevistados mencionaram tal estímulo para dar início à caminhada. Nessa perspectiva, o peregrino 44 afirmou: "Conhecer pessoas de diferentes países".

Dentre as principais razões, a busca pelo autoconhecimento também se destaca. Nove peregrinos vincularam sua motivação à busca por momentos de autorreflexão e estarem sozinhos em um processo. Sobre esse aspecto, destaca-se a fala de um dos entrevistados:

É a única vez que você realmente cuida de si mesmo, e, sobretudo te escuta a nível do corpo, então, se você estiver cansado você para, se você estiver com sono, dorme, se estiver com fome, come, então você está livre, você se sente livre, e com respeito a sua vida diária, sobre o seu tempo. Portanto se você tem um relacionamento com você mesmo, precisa do primário, porque somos animais, precisamos de pouco, comemos, dormimos e passamos bem com nós mesmos. (PEREGRINO 31).

A fé, espiritualidade e/ou religiosidade, também aparecem, como motivação para a peregrinação, visto que quatorze peregrinos relataram que decidiram realizar o caminho por motivos religiosos e/ou espirituais. Sobre esse conceito, um dos entrevistados disse: "[...] porque no passado eu não tinha confiança em Deus, e através da minha viagem eu aprendi a confiar, pois o Caminho me ensinou a confiar nele." (PEREGRINO 3). Diante dessa perspectiva, cada vez mais estudos tem apontado a influência positiva da espiritualidade na saúde física, mental e social dos indivíduos. Em 1988, a Organização Mundial de 
Saúde (OMS) despertou para o interesse em aprofundar as investigações na área da espiritualidade como influenciadora na saúde física dos indivíduos, citando questões como significado e sentido da vida, e não se referindo somente a um tipo específico de crença ou prática religiosa ${ }^{29}$.

Além dos motivos citados acima, três entrevistados mencionaram o esporte e o turismo como principal estímulo. Dois peregrinos relataram que problemas pessoais motivaram a decisão e quatro não souberam explicar o que os levou a realizar o caminho. Nesse sentido, Duarte ${ }^{2}$ destaca que os peregrinos buscam o itinerário por diferentes motivos, indo além do enfoque religioso-espiritual, mas turístico-patrimonial, cultural, paisagístico ou mesmo esportivo.

Os entrevistados, ainda, falaram dos impactos que a longa jornada proporcionou na constituição da sua identidade. Sobre essa categoria, trinta e nove entrevistados disseram que as principais transformações percebidas durante e ao fim do percurso foram a empatia, a solidariedade, o equilíbrio emocional, o autoconhecimento, o desapego, a socialização e o contato com a espiritualidade. A capacidade de desenvolver e cultivar esses valores e princípios, antes esquecidos ou ignorados em suas vidas cotidianas, foi citado como impacto positivo pela maioria dos entrevistados. Mediante ao exposto, um dos participantes relatou: "Me sinto mais realizada, tenho mais confiança em mim mesma, não sabia que poderia concluir o Caminho, aumentou minha autoestima." (PEREGRINO 17). Outro peregrino acrescentou: "[...] o Caminho me fez aproximar e entender as pessoas, modo de pensar, viver e ver a vida, antes eu não entendia, mas agora entendo". (PEREGRINO 36). Ainda sobre esse prisma, outro entrevistado expôs: "Cada dia pensava que chegava mais perto de Santiago, e a cada dia que eu andava sentia que formava mais a minha identidade". (PEREGRINO 28). Entretanto, dez entrevistados mencionaram que até 0 momento não haviam percebido nenhum impacto ou efeito significativo em sua maneira de agir e/ou pensar.

Os estudos realizados por Gallegos ${ }^{30}$ afirmam que muitos peregrinos descrevem uma desconexão com a vida cotidiana, permitindo, assim um encontro com o seu equilíbrio e paz interior. Segundo o autor, a função de realização pessoal que muitos atribuem ao Caminho de Santiago é algo autêntico e real. Ainda sobre essa categoria, um peregrino descreveu que o maior impacto sentido por ele foi a 
sua integração com a natureza. "Gosto da natureza, da tranquilidade da natureza, gosto de ouvi-la, vê-la e senti-la." (PEREGRINO 10). Para Rosendahl e Correa ${ }^{31}$ :

[...] as peregrinações são descritas como experiências que podem proporcionar aos peregrinos "conhecimento de si mesmos", "introspecção", "despojamento material" em uma dimensão mais subjetiva. Mas também pode favorecer o contato dos peregrinos com "paisagens", com uma "natureza exuberante" e com "belos quadros da natureza".

No que se refere às experiências que a realização do Caminho proporcionou aos peregrinos, vinte e sete descreveram que os momentos de silêncio e solidão possibilitaram uma maior compreensão do sentido de suas vidas. Sobre esse aspecto, destaca-se a fala de um dos entrevistados: "[...] se sentir isolado, eu gosto da solidão, e isso o Caminho te traz muito, por isso fiz o Caminho. Uma pessoa necessita saber estar só." (PEREGRINO 19). Referente a esse discurso, Clift e Clift $^{17}$ afirmam que a peregrinação propõe um crescimento e desenvolvimento interior, ampliando a personalidade e a visão do mundo, desse modo, o ato de peregrinar é capaz de transformar o indivíduo através de algo que o transcende.

Relacionar-se com pessoas de diferentes culturas, foi citado por dezesseis entrevistados como a maior experiência que o caminho thes propiciou. Sobre esse aspecto, o peregrino 28 acrescentou: "[...] companheirismo, amizades, conhecer pessoas novas e ter experiências novas". Nessa mesma ótica, outro entrevistado disse: "Experiências com as pessoas, este Caminho teve uma aproximação emocional e humana, senti que recebia muito das pessoas, como se eu já as tivesse conhecido." (PEREGRINO 13). A diversidade de peregrinos, vindo de diferentes países com culturas e crenças próprias, torna o trajeto enriquecedor. A troca de experiências auxilia o indivíduo a enfrentar situações não somente no caminho físico, mas contribui para resolução de conflitos que poderão surgir em suas vidas ${ }^{32}$.

Três peregrinos relataram que o contato com a natureza foi a experiência mais significativa que tiveram. "Entrar em um espaço desconhecido, na natureza, campos". (PEREGRINO 14). Conquanto, apesar das múltiplas e particulares vivências que a jornada pode proporcionar, quatro dos cinquenta entrevistados afirmaram não ter tido experiência alguma com a concretização do caminho.

Diante do contexto exposto, pode-se perceber que o Caminho de Santiago se tornou uma busca pelo equilíbrio físico e mental que muitos indivíduos 
não encontram em sua rotina diária. Segundo os estudos de Martín e Monteserín ${ }^{28}$, os peregrinos descrevem várias razões para esta misteriosa transformação: o encontro com outros peregrinos, as experiências singulares, a observação da natureza e lugares históricos, ou talvez a fadiga, os calos nos pés, a insônia, e o ritmo lento da prolixa caminhada.

\section{CONCLUSÃO}

Este estudo procurou identificar os aspectos psicossociais que envolvem o Caminho de Santiago a partir dos depoimentos de cinquenta indivíduos que percorreram um dos percursos até chegar em Santiago de Compostela. Após análise de todas as respostas, atestou-se que o Caminho de Santiago e a saúde mental possuem relações estreitas, visto que muitos peregrinos buscam no itinerário solução para situações cotidianas que em sua rotina não conseguem encontrar. De acordo com Vergote ${ }^{17}$, , [...] a experiência da peregrinação requer certas condições (psicológicas, culturais e religiosas) e só quem a ela se dispõe a fará efetivamente". Tal afirmação demostra o quão particular e subjetiva é a escolha de deslocar-se para essa experiência, pois envolve fatores que vão além de uma simples caminhada.

Faz-se necessário destacar que os objetivos iniciais desta pesquisa foram alcançados, porque foi possível demonstrar que essa peregrinação ultrapassa as razões religiosas ou espirituais, de modo que inclui a busca pelo autoconhecimento, novas amizades, experiências sócio afetivas, esporte, turismo ou, simplesmente, o contato com elementos da natureza. Silva e Santos ${ }^{11}$ afirmam que o peregrino que decide percorrer o caminho, submete-se a encontrar algo além do seu cotidiano, podendo experienciar uma transformação interior.

Os impactos que essa jornada produz naqueles que decidem percorre-la também são diversos. Os entrevistados mencionaram a empatia, a solidariedade e a sensação de bem estar como transformações sentidas durante e após a caminhada.

De acordo com o Inventário de Estado de Humor - POMS ${ }^{33}$, aplicado nos peregrinos após sua chegada, a fadiga teve a maior média, seguido de vigor, com uma média menor e em ordem decrescente, a raiva, a depressão, a tensão e a 
confusão mental. Os resultados do MEEM indicaram que nenhum dos cinquenta entrevistados apresentaram prejuízos cognitivos.

As experiências vivenciadas abrem para um conjunto de indagações, pois se observou que alguns peregrinos, sem nenhum comprometimento nas suas funções cognitivas ou transtornos mentais relatados, vivenciaram situações anômalas, como alterações na percepção do tempo e/ou espaço, ouvir vozes e/ou ver imagens durante a caminhada. Os estudos realizados por Dalgalarrondo ${ }^{7}$ afirmam que existe uma diferença entre experiências espirituais e sintomas psicopatológicos. Segundo o autor, deve-se observar: o conteúdo e a duração das vivências, as particularidades das experiências sensoriais, o grau de insight, orientação em relação a outras pessoas, estilo de vida e personalidade daquele que está vivenciando tais experiências.

Os resultados desse estudo apontam que Caminho de Santiago pode proporcionar algumas transformações naqueles que se propõem a concretizá-lo. Não obstante, após superarem a jornada, o fato de essa possível transfiguração perder força ou deixar de existir quando os peregrinos voltam para suas casas, podem abrir para outras questões de saúde mental, como uma possível depressão pós-caminho, devido a nostalgia que a experiência deixou ou as mudanças almejadas não haverem perdurado.

\section{REFERÊNCIAS}

1. Lois González RC, López L. El Camino de Santiago: Una aproximación a su carácter polisémico desde la geografía cultural y el turismo. [Internet]. Documents d'Anàlisi Geogràfica, [S.I.], v. 58, n. 3, p. 459-479, oct. 2012. ISSN 2014-4512. [acesso em 2017 out 28]. Disponível em: <http://dag.revista.uab.es/article/view/v58n3-lois-lopez/6>.

2. Duarte ACF. Caminhos de Santiago: o Caminho Português como fator de desenvolvimento turístico no concelho de Barcelos. [Internet]. [Dissertação]. [Porto]: Faculdade de Letras. Universidade do Porto; 2016. 122 p. [acesso em 2017 ago 05]. Disponível em: <file:///C:/Users/User/Downloads/Dissertacao_Caminhos_de_Santiago\%20(8).pdf>

3. López JL et al. (2010) - Peregrinaciones y turismo. El Camino de Santiago. [Internet]. ROTUR / Revista de Ocio y Turismo, №3, p. 39-48. [acesso em 2016 out 18]. Disponível em: <file:///C:/Users/User/Downloads/DialnetPeregrinacionesYTurismo-3610319.pdf>. 
4. Farinha H. O Caminho de Santiago: Caminho del Norte na Cantábria. [Internet]. [Dissertação]. [Coimbra]: Faculdade de Letras. Universidade de Coimbra; 2013. 25 p. [acesso em 2017 jul 25]. Disponível em: <http://www.academia.edu/14920192/O_Caminho_de_Santiago_e_a_Cant\%C3\%A1 bria>.

5. Mendes AC. Peregrinos a Santiago de Compostela: uma etnografia do Caminho Português. [Dissertação]. [Lisboa]: Instituto de Ciências Sociais Universidade de Lisboa; 2009. 80p.

6. Dalgalarrondo P. Religião, psicopatologia \& saúde mental. Porto Alegre: Artmed, 2008. 288p.

7. Dalgalarrondo P. Psicopatologia e semiologia dos transtornos mentais. $2 a$ ed. Porto Alegre: Artmed, 2008. 438 p.

8. Cardoso AH; Almeida, Lourenço de. O Caminho Português de Santiago. Cascais: Editora Lucerna. $153 \mathrm{p}$.

9. Mourthé A. História e colapso da civilização: é melhor o incômodo da advertência que a tragédia da ignorância. 1a ed. Rio de Janeiro: Editora Mourthé, 2014. 704 p.

10.Torre MGMV et al. (2010). Turismo religioso: estudio del Camino de Santiago. [Internet]. Gestión Turística № 13, junho, pp. 9-37. [acesso em 2017 set 25]. Disponível em: <http://mingaonline.uach.cl/pdf/gestur/n13/art01.pdf>.

11. Silva MCC, Santos TC. Peregrinação, experiência e sentidos: uma leitura de narrativas sobre o Caminho de Santiago de Compostela. [Internet]. Revista da Associação Nacional dos Programas de Pós-Graduação em Comunicação | Ecompós, Brasília, v.18, n.2, maio/ago. 2015. [acesso em 2017 jul 10]. Disponível em: <http://www.compos.org.br/seer/index.php/e-compos/article/viewFile/1198/846>.

12. Sampaio, JJC. Epidemiologia da imprecisão: processo saúde/doença mental como objeto da epidemiologia. [Internet]. Rio de Janeiro: Editora Fiocruz, 1998. [acesso em 2017 set 25]. Disponível em: <http://books.scielo.org/id/3vxfc/pdf/sampaio-9788575412602-07.pdf>.

13. Machado R. Danação da norma: medicina social e constituição da psiquiatria no Brasil. Rio de Janeiro: Graal. 1978. 559 p.

15. Minayo MCS. O desafio do conhecimento: pesquisa qualitativa em saúde. 2a ed. São Paulo: Hucitec, 1993. 269 p.

16. Murakami R, Campos CJG. Religião e saúde mental: desafio de integrar a religiosidade ao cuidado com o paciente. [Internet]. Rev. bras. enferm., Brasília, v. 65, n. 2, p. 361-367, Apr. 2012. [acesso em 2017 out 18]. Disponível em: <http://www.scielo.br/scielo.php?script=sci_arttext\&pid=S0034-

$71672012000200024 \&$ Ing $=$ en\&nrm=iso $>$. 
17. Cardita A. Peregrinação: possibilidades de compreensão crítica de uma experiência. [Internet]. Sociologia. Porto, v. 24, p. 195-213, dez. 2012. [acesso em 2017 out 15]. Disponível em: $<$ http://www.scielo.mec.pt/scielo.php?script=sci_arttext\&pid=S0872$34192012000200010 \& \operatorname{lng}=\mathrm{pt} \& \mathrm{nrm}=$ iso $>$.

18. Werneck FZ, Navarro CA. Nível de atividade física e estado de humor em adolescentes. Psic.: Teor. e Pesq., Brasília, v. 27, n. 2, p. 189-193, 2011. [acesso em 2017 out 12]. Disponível em: $<$ tttp://www.scielo.br/scielo.php?script=sci_arttext\&pid=S0102$37722011000200010 \& \operatorname{lng}=$ en\&nrm=iso $>$.

19. Steil CA, Toniol R. Ecologia, corpo e espiritualidade: uma etnografia das experiências de caminhada ecológica em um grupo de ecoturistas. [Internet]. Cad. $\mathrm{CRH}$, Salvador, v. 24, n. 61, p. 29-49, Apr. 2011. [acesso em 2017 jul 17]. Disponível em: <http://www.scielo.br/scielo.php?script=sci_arttext\&pid=S0103$49792011000100003 \& \operatorname{lng}=$ en\&nrm=iso $>$.

20. Steil CA, Carneiro SS. Peregrinação, turismo e nova era: caminhos de Santiago de Compostela no Brasil. [Internet]. Relig. soc., Rio de Janeiro, v. 28, n. 1, p. 105124, July, 2008. [acesso em 2017 jul 15]. Disponível em: $<$ http://www.scielo.br/scielo.php?script=sci_arttext\&pid=S0100$85872008000100006 \&$ Ing $=$ en\&nrm=iso $>$.

21. Sampieri RH et al. Metodologia de pesquisa. 5a ed. Porto Alegre: Penso, 2013. $624 \mathrm{p}$.

22. Creswell JW. Projeto de pesquisa: métodos qualitativo, quantitativo e misto / John W. Creswell; tradução Luciana de Oliveira da Rocha. 2a ed. Porto Alegre: Artmed, 2007. 248 p.

23. Richardson RJ. Pesquisa social: métodos e técnicas. São Paulo: Atlas, 1999. $334 \mathrm{p}$.

24. Rohlfs ICPM et al. A escala de humor de Brunel (Brums): instrumento para detecção precoce da síndrome do excesso de treinamento. [Internet]. Rev Bras Med Esporte, Niterói, v. 14, n. 3, p. 176-181, June, 2008. [acesso em 2017 set 13]. Disponível em: <http://www.scielo.br/scielo.php?script=sci_arttext\&pid=S1517$86922008000300003 \& \operatorname{lng}=$ en\&nrm=iso>.

25. Folstein $\mathrm{M}$ et al. Mini-estado mental: um método prático para classificar o estado cognitivo dos pacientes para o clínico. [Internet]. J Psychiatric Res. 1975; 12: 189-98. [acesso em 2017 set 12]. Disponível em: $<$ http://www.journalofpsychiatricresearch.com/article/0022-3956(75)90026-

6/abstract>.

26. Oficina del Peregrino. [acesso em 2017 out 20]. Disponível em: <https://oficinadelperegrino.com/estadisticas/> 
27. Martin JJG, Monteserin A. Patología psiquiátrica en peregrinos del Camino de Santiago. Servicio de Psiquiatría y Servicio de Atención al Paciente - Complejo Asistencial de Burgos. No prelo.

28. Martinez SR. A psique do Caminho: psicanálise e individuação no Caminho de Santiago de Compostela. Foz do Iguaçu: Clube dos autores, 2016. 239 p.

29. Volcan SMA et al. Relação entre bem-estar espiritual e transtornos psiquiátricos menores: estudo transversal. [Internet]. Rev. Saúde Pública, São Paulo, v. 37, n. 4, p. 440-445, Aug. 2003. [acesso em 2017 out 19].

$<$ http://www.scielosp.org/scielo.php?script=sci_arttext\&pid=S0034-

Disponível em: $89102003000400008 \& \operatorname{lng}=$ en\&nrm=iso $>$.

30. Gallegos AG. El Camino de Santiago: Guia de vivencias del peregrino del siglo XXI. Sevilla: Wanceulen, 2010. 213 p.

31. Rosendahl Z, Corrêa RL (Orgs.). Geografia cultural: uma antologia, volume II. Rio de Janeiro: EdUERJ, 2013. 344p.

32. Agrêla D. O guia do viajante do Caminho de Santiago: uma vida em 30 dias. São Paulo: Évora, 2013. 192p.

33. Viana MF, Almeida PL, Santos RC. Adaptação portuguesa da versão reduzida do Perfil de Estados de Humor: POMS. [Internet]. Aná. Psicológica, Lisboa, v. 19, n. 1, p. 77-92, 2001. [acesso em 2017 set 20]. Disponível em: $<$ http://www.scielo.mec.pt/scielo.php?script=sci_arttext\&pid=S0870-

$82312001000100008 \&$ lng $=$ pt\&nrm=iso $>$.

34. OMS. Relatório sobre a saúde no mundo: saúde mental nova concepção, nova esperança. 2001. [internet]. [acesso em 15 de outubro de 2017] Disponível em: https://www.dgs.pt/upload/membro.id/ficheiros/i006020.pdf. 